\title{
Balancing Discretion and Expansion in the União do Vegetal
}

\author{
Jake Ference \\ University of Florida
}

Faculty Mentor: Robin Wright, Department of Religion

\begin{abstract}
The União do Vegetal (UDV) is an ayahuasca-based religion that operates with an unusual amount of discretion. Preliminary research into the group created a desire to develop a better understanding of how the UDV balances its own ideas of acceptance and expansion while remaining discreet and closed to outsiders. This context of discreeetness has been shaped by the group's history of legal prosecution and hesitant religious acceptance in the cultures into which it has expanded into, rather than group beliefs or practices. Through literary analysis of research papers on the UDV, general group secrecy, and interviews with members, this project will analyze why these practices are so pervasive. This research concludes that the UDV's usage of discretion is a legitimate response to the legal and social pressures that the group faces, and while secrecy does not appear to be an integral part of the group, discretion does play an important role in member interaction with outsiders. Additionally, this research suggests that the UDV's expansion indicates an overlap with New Age spiritualities.
\end{abstract}

Keywords: Ayahuasca, UDV, New Age, secrecy, legality

\section{Introduction}

The União do Vegetal (UDV) was founded in Porto Velho, Brazil in 1961 by José Gabriel da Costa, later referred to by followers as Mestre Gabriel. The group was founded as a blend of Catholicism, Afro-Brazilian tradition, and Amazonian shamanism (Labate, Rose, \& Santos, 2009). While already being unique for its complex organizational model and religious structure which will be discussed later, the group has further become identified by its usage of the psychoactive known as ayahausca, also known as hoasca tea, in its religious practices. The usage of hoasca tea is considered the main sacrament of the faith, and members believe that the brew will give the user the mental concentration needed to become closer to God (Labate \& Cavnar, 2014). The UDV is highly organized, with volunteer-based elections for leaderships. Regular members are divided into four categories of varying standing within the religion, while each congregation, referred to as a nucleo, has a mestre, a spiritual leader, who represents and directs the congregation. Every country where the organization is found has its own leadership positions 
as well as an overall organizational structure for the entire group that originates in Brazil (Henman, 2009).

While the UDV now has congregations in 10 countries with around 20,000 members, English anthropological literature about the group is sparse and becoming involved in the group can be difficult (Labate, Cavnar, \& Gearin, 2017). In attempting to join the group to conduct this ethnographic project, many bars to entry were encountered for new members and researchers. These practices led to questions regarding the motivations and reasoning behind them and the development of an understanding of how the group balances its ideas of acceptance and expansion while remaining discreet. This tendancy towards discreetness has been shaped by the history of the group and its prosecution for its beliefs. This paper argues that the UDV's usage of secrecy is a reasonable reaction given the group's history and external pressures, as well as explaining its expansion despite this context. This paper starts by looking at the ways secrecy has manifested itself within the UDV, why history may have shaped its relationship to discretion, and why outsiders and researchers are presented with so many barriers to entry. Finally, this relationship is discussed in the wider context of current New Age spirituality and globalization to explain what role the UDV has in the changing religious landscape.

\section{Understanding Secrecy in the UDV}

Secrecy is something that from the outside appears integral to the UDV, but this is an image that the group has attempted to distance themselves from. In a self-published piece, the UDV is presented as "not a secret society, although at many times in its history it has acted in a discreet manner in the pursuit of its interests," (UDV, 2018, 8). This statement highlight that the group considers itself not secretive but rather "discreet". This distinction is significant because calling the UDV a secret society is misleading. The UDV is a group that, similar to other societies generally considered "secret," directly interacts with the outside world (Mahmud, 2014). The UDV has agreements with government agencies, is registered as a religious non-profit, and has a number of websites, blogs, and publications. Public tax documents about the congregations are also available online, but can be difficult to find. While secretive in its relationship to the public, the organization itself is only as "secret" as its small and practically unknown public image allows. In Brazil, the UDV is well-known and would not be considered secret, but its practices may still be considered discreet. How the UDV's practices can be separated into being discreet, secretive, or some combination of both is difficult to determine, but for the purposes here, the 
group has described itself as using discretion at times in its history, and this gives it a direct relationship with secrecy. The UDV still appears to go to great lengths to achieve a certain level of discretion, which can be seen in the ways the organization has chosen to interact with outsiders.

The process of joining the group illustrates this interaction. From personal experience and discussions with interlocutors, joining the UDV starts with finding contact information for the congregation, which is not published anywhere publically that could easily be found. The only way to obtain this information is to know someone familiar with the group, and possibly the exact congregation. If the newcomer's contact to the group is a congregation member they may be able to have that member act as a sponsor who will assist them in gaining access to the group. Without the assistance of a member, newcomers may only receive an email address for the congregation's secretary and will need to email a representative. Afterward, waiting for a reply, which for this project took four months to receive, before meeting with a representative of the congregation in-person, which took an additional three months to plan. From there, researchers need to submit a typed research proposal outlining their project which will go to organization leaders in the United States (US), Brazil, and the UDV scientific committee which evaluates the proposed research and can either approve, approve with restrictions, or reject the project ( $\mathrm{S}$, personal communication, July 15, 2019; UDV, 2019). This process could take anywhere from a few weeks to several months based on this study, but that large range of time may be due to the circumstance and contacts that were relied on here, and not representative of the organization. If the newcomer is not a researcher and is approved to start taking part in the congregation, then they have to wait for a newcomer meeting which only takes place every three to four months and must be attended before being able to go to regular congregation meetings $(\mathrm{S}$, personal communication, July 15, 2019).

After this process is complete, one may attend congregation events regularly. The congregations have no listed address, and in Gainesville, they meet in an unmarked rented space that is paid for by member donations each month (S, personal communication, July 15, 2019). Outside the US, the organization has similar practices. The barriers to entry are usually bureaucratic but may also be physical. According to Dr. Mentor name from University of Florida, the main congregation in Campinas, Brazil, has a tall, brick wall with barbed wire and cameras surrounding the entire complex. The organization even across multiple countries 
appears to act with a certain level of discretion, meaning a level of disconnection from the public.

Despite these barriers, the UDV is not a typical religious secret society. The idea of having outsiders excluded based on certain roles in society, gender, or lineage is not present here as can be found in some religious societies (Bellman, 1984). Membership does not seem barred by any socio-cultural trait or status, and most of the steps to join are not hard besides initially obtaining the contact information. While high expectations do seem to be placed on proposals, at no point was the one-page proposal required by University Scholars questioned as illegitimate, and, even after the UDV declined to work with this project, the leader did extend an invitation to get take part in the congregation outside of research interests. For the most part, it seems that anyone can join, but the group is very selective of who they choose to trust, as well as who can and cannot conduct research on the organization. While other societies such as the Freemasons may have secrecy as a central part of their rituals, (Mahmud, 2014), the UDV's secrecy appears to be more procedural, linked to the actual running of the organization rather than being a inherent part of the faith. This may be why the group tries to downplay the importance of secrecy, because it is not an essential element of the faith, but rather a measure to protect the organization.

\section{Possible Reasonings for Organizational Secrecy}

One important component to understanding the UDV's discretionary practices relates to the group's history. Originally, the group was persecuted by the Brazilian government during a time of intense official disapproval of "drugs" (Henman, 2009). According to Christina Callicott (online interview, February 24, 2020), an ex-member of the Gainesville church and recent $\mathrm{PhD}$ in the University of Florida Department of Anthropology, today the relationship between the UDV and the governments with which they are involved is stronger. However, this relationship can very easily change if the government decided to start prosecuting the UDV's religious usage of ayahuasca (Henman, 2009). Under the strong anti-drug policy of the current Bolsonaro administration this outcome is not unlikely. Even today, Mestre Gabriel's arrest in Brazil during the 1960s is still used as a warning to members about the authorities' outlook on the UDV (Labate, 2012).

These troubles have extended into countries whithin which the UDV has expanded as well. The organization spent years in court fighting for religious freedom in the US. In 1999, the United States UDV president's office was raided in Santa Fe, New Mexico, and hoasca tea was 
seized. Seven years of litigation and a U.S. Supreme Court case would eventually lead to the UDV winning religious acceptance in 2006 (Labate, 2012). After this, the UDV and the United States Drug Enforcement Agency created a 20-page document outlining exactly what the organization must do in order to be able to use ayahuasca, such as producing written records of all imports, quantity of people who take the tea, and its total volume, storage location, and ownership (Labate, 2012). This history may point to one of the first reasons why secrecy is so prevalent: for the group's protection. Since the anthropology of secrecy began, protection has been seen as the most significant purpose of maintaining secrecy (Simmel, 1906). When it comes to seeking that protection, Simmel theorized the "most radical of all the protective provisions is certainly that of invisibility" (Simmel, 1906, 470). The UDV may not merely be trying to separate itself from outsiders, but rather its history points to a degree of prosecution against which it seeks protection. It may be that the UDV has decided to be "invisible" to achieve this goal.

This reasoning manifests itself in two ways. The first is the UDV's disregard for trying to bring in new members and its lack of recruitment (UDV, 2018). Whether this is necessarily a part of the group's secrecy with the hope of distancing members from outsiders, or just trying to avoid convincing people to subscribe to their ideas, is difficult to discern as an outsider. However, independent of the reason, this action does have reasonable explanations when looking at the organization's structure and shortcomings. Bringing in newcomers has also raised concerns amoung members about acquiring more hoasca tea, with worries of environmental sustainability issues and increased government interaction threatening UDV religious practices (Labate, 2012; S, personal communication, July 15, 2019).

Another reason could be that prosecution has made the UDV fearful of what could happen in other countries or to places like the U.S. if it expands and has one mistake ruin its legal standing. The idea of invisibility outlined by Simmel is not as literal as trying to be completely secret to outsiders, because members are not barred from discussing their faith with non-members. Instead, they have tried to remove themselves from the public eye enough that it takes effort to find them. It could be that the UDV is not confident in its own influence and strength as an organization to be protected without being discreet (Simmel, 1906), or it could be an artifact of the past developed as a result of the prosecution the group once faced. 
This does not mean that secrecy or discretion is something that is integrated into the group. With a history of court cases in favor of the UDV across multiple countries, the organization recognizes that its worries of prosecution at this point are more individually based, not government or federal based (Callicott, online interview, February 24, 2020). Rather, the UDV does not want to discuss its beliefs or talk about members of the church with the public in order to protect those members from the possibilities of bias or prejudice (Callicott, online interview, February 24, 2020). There is no official request for these actions, but rather it is an attempt to be respectful towards friends and to protect the image of the church.

While looking for interviews for this project, a post was created on the Reddit page r/Ayahuasca to see if any UDV members who frequented the site would be interested in discussing their religion for this project. In their initial response to the request for an interview, someone claiming to be a UDV member said, "I would not give the name or number of any member of the UDV out under any circumstance" (Author, Online fourm post, December 8, 2019); This member raised several questions about this research that they needed answered before they would be interviewed (researcher credentials, who in the UDV had already been spoken to). This relationship with discretion is clearly very prevalent within the organization even without an organizational structure to support it (at least with lower-level members). Combined with the possible prejudice from the public due to the legal prosecution faced up to this point, keeping a low level of publicity makes a lot of sense.

So how does this shape "the bar" to entry for newcomers? Joining other mainstream religious organization, specifically other Christian faiths in the US, is easy, and often begins with the simple act of coming to congregations in many cases. This uniqueness of the UDV may stem from wanting to ensure the utmost responsibility for their faith given the context where some government agencies still do not see their faith as entirely legitimate (Labate, 2012). This project was shaped by the very specific nature of the Gainesville congregation, so partly this response takes place within that context. Making it difficult to become a member makes sense in the context of a religion that uses a psychoactive, especially within a college town. One of the first questions that was asked by organization representative $S$ was why the project was focused on the UDV and what the intentions for the research were. After explaining previous experience with ayahuasca in a shamanic context as well as the desire to do long-term research, he revealed that they always ask to make sure people are interested in the religion itself and not to just "get 
high.” (S, personal communication, July 15, 2019). Creating not incredibly difficult but still substantial barriers to entry ensures that those with poor intentions are more likely to be pushed away from the organization. This not only protects against those hoping to take advantage of faith, but also minimizes the risk of the tea being misused outside of a religious context.

Additionally, the UDV does not try to downplay what they use in ceremony. Ayahuasca is a strong hallucinogen. No matter the religious beliefs, a proper introduction is a necessity for firsttime users, and thus, a newcomer's meeting is necessary. So, there is strong rationale behind the integration of new members. The bars to research do seem a bit harsh from the outside, but there are reasons to make it difficult for researchers to enter the faith. Anthropology has a long of history that readily shows the dangers that social scientist can bring to marginalized communities, and beyond that, why should the UDV allow outsiders to conduct the research? The UDV does not wish to expand, and the group seems fairly tight-knit based on how the organization is structured. What do they gain from working with academics? They do not want publicity, and being published in a paper is a risk that puts back religious freedom efforts by years. The medical research they do interact with regularly brings legitimacy to the usage of hoasca tea as a safe practice (Labate, 2012), but social science research is largely absent. Their refusal to work with outside social scientists may be able to explain this practice. In Audra Simpson's piece on ethnographic refusal, she concluded that people refusing to take part in ethnographic research can tell researchers just as much about a group as actually knowing its secrets (Simpson, 2007). The UDV is a strong, independent organization that has not only fought for itself for many years, but has also decided the scope of research within itself on its own terms. It gives them agency in what role they have in their own literature, and their refusal helps to shape that literature to clarify the relationship they want to have with the outside. Refusal is not only used to protect the group from prosecution, but may also protect the group's sovereignty and ability to make their own decisions, despite the role academics and governments hope to play in their beliefs (Simpson, 2007). Working with outsiders does not seem to be in the best interest of the group, and it seems they structure their interaction with the public as being satisfied with where they are, not wanting to change the organization on the terms of others.

\section{An Alternative and the New Age of Spirituality}

Why has the UDV continued to expand despite keeping a certain level of discretion and not wanting to grow its membership? Originally, immigration to the U.S. from Brazil was thought to 
be the main driver for the growth of the UDV, but places like the Colorado congregation have almost no Brazilians (Callicot, online interview, February 24, 2020). Rather, the growth is associated with a growing awareness of not just the organization itself, but ayahuasca as a whole. The West (US and Europe) has become increasingly interested in psychedelics since the socalled psychedelic revolution of the 1960s; although at the time, ayahuasca remained almost entirely unknown outside of the South American communities where it was common. It was not until the last few decades during which globalization and the exchange of cultural knowledge spread like wildfire that ayahuasca found its place among the natural hallucinogens that are familiar in the US today, like peyote or psilocybin (Tupper, 2008). This awareness has grown in tandem with the changes in popular spirituality across the US as well, which leads into why the UDV has been so successful beyond its usage of ayahuasca.

Besides the widespread revival of interest in psychedelics across the U.S., the UDV is appealing to people who are religious but do not derive satisfaction from established religions. The UDV is a syncretic religion with deep roots in Catholicism, and for many people, large organized religions are not as appealing as they used to be. The UDV offers a highly structured faith similar to other sections of Christianity, while remaining smaller and more manageable. Unlike other neoshamanic New Age models for spirituality, the UDV has not based its beliefs on interpretations of indigenous forms of spirituality. The relationship between the UDV and the indigenious groups that ayahuasca comes from is largely absent, especially compared to other ayahuasca religions (Labate, Rose, \& Santos, 2009). While the UDV has been described as incorporating Amazonian shamanism (Labate, Rose, \& Santos, 2009), it can be argued that, given the lack of an indigenous or shamanic connection, it may be incorrect to call it a neoshamanic New Age religion. In this regard, Callicott stated that members prefer a system like the UDV over neoshamanic groups, because the hierarchy of authority means there is a system of power that can keep the organization running, unlike "a bunch of hippies in a room where no one is really in charge," (Callicot, online interview, Feburary 24, 2020). Callicott was quite clear that the UDV understands that ayahuasca is not appropriate for everyone, and that members are free to leave at any time, like Calicott did. Combine this aspect with the UDV not wanting to expand, unlike Catholicism or other religions in the U.S., and it becomes very appealing to those unsatisfied with the conventions of most organized religions. It would appear that the very 
conventions that make the UDV seem so secretive are its most appealing feature that has continued to drive its expansion over the last 20 years.

\section{Conclusion}

The UDV acts as a modern example of how secrecy can manifest itself within a group. The organization's secrecy is not based on wanting to distance the initiated from outsiders, but rather on a desire to remain undetected and protected from those in power who are perceived as threats against everything the group has strived to attain. The history of the UDV shows the reasons they may have adopted measures towards remaining discreet, and contributes to explaining a group that is wary of outsiders but is also consistently expanding overseas. The group's discreet practices are comprehensible reactions, given the status of the group here in the U.S. as well as other places where congregations are found. These actions have been incredibly important in creating a group identity that can satisfy the needs of many looking for new forms of spirituality, rather than a group trying to hide its practices from the public.

\section{Acknowledgements}

This paper would not have been possible without a few individuals. my mentor Dr. Robin Wright in the Religion Department, who helped develop and refine this project from the beginning. Dr. Alix Johnson in the Anthropology Department, the one who introduced me to the anthropology of secrecy and someone I see as a role model for anthropology. Christina Callicott, who helped me better understand the UDV from an insider perspective, which this project so desperately needed for the longest time. And especially the UDV, for treating this investigation as a legitimate project despite its simplicity and my missteps along the way.

\section{References}

Bellman, B. L. (1984). The Language of Secrecy: Symbols \& Metaphors in Poro Ritual. New Brunswick, NJ: Rutgers University Press.

Centro Espírita Beneficente União do Vegetal. (2018). The Right for the Religious Use of Hoasca Tea. Centro Espírita Beneficente União do Vegetal. Brasília, Brazil.

Centro Espírita Beneficente União do Vegetal. (2019). Research and Article Submission. Centro Espírita Beneficente União do Vegetal. Brasília, Brazil.

Henman, A. R. (2009). Ayahuasca Use in a Religious Context: The Case of the União do Vegetal in Brazil. Erowid.org. 
Author. [Author]. (2019, December 8th). UDV members interested in talking for research? [Online fourm post].

https://www.reddit.com/r/Ayahuasca/comments/e7yfi1/udv_members_interested_in_talking_f or_research/

Labate, B. C., de Rose, I. S., \& dos Santos, R. G. (2008). Ayahuasca Religions: A Comprehensive Bibliography and Critical Essays. Santa Cruz, CA: Multidisciplinary Association for Psychedelic Studies.

Labate, B. C. (2012). Paradoxes of Ayahuasca Expansion: The UDV-DEA Agreement and the Limits of Freedom of Religion. Drugs: Education, Prevention \& Policy, 19(1), 19-26.

Labate, B. C., \& Cavnar, C. (2014). The Therapeutic Use of Ayahuasca. Berlin: Springer.

Labate, B. C., Cavnar, C., \& Gearin, A. K. (2016). The World Ayahuasca Diaspora: Reinventions and Controversies. Abingdon: Routledge.

Mahmud, L. (2013). The Profane Ethnographer: Fieldwork With a Secretive Organisation. Organisational Anthropology. London: Pluto Press.

Mahmud, L. (2014). The Brotherhood of Freemason Sisters: Gender, Secrecy, and Fraternity in Italian Masonic Lodges. Chicago, IL: The University of Chicago Press.

Simmel, G. (1906). The Sociology of Secrecy and of Secret Societies. American Journal of Sociology, 11(4), 441.

Simpson, A. (2007). On Ethnographic Refusal: Indigeneity, 'Voice' and Colonial Citizenship. Junctures: The Journal for Thematic Dialogue, 9, 67.

Tupper, K. W. (2008). The Globalization of Ayahuasca: Harm Reduction or Benefit Maximization? International Journal of Drug Policy, 19(4), 297-303. 